\title{
Dentoalveolar mandibular changes with self-ligating versus conventional bracket systems: A CBCT and dental cast study
}

\author{
Marcio Rodrigues de Almeida', Cristina Futagami², Ana Cláudia de Castro Ferreira Conti³, \\ Paula Vanessa Pedron Oltramari-Navarro¹, Ricardo de Lima Navarro ${ }^{4}$
}

DOI: http://dx.doi.org/10.1590/2176-9451.20.3.050-057.oar

Objective: The aim of the present study was to compare dentoalveolar changes in mandibular arch, regarding transversal measures and buccal bone thickness, in patients undergoing the initial phase of orthodontic treatment with self-ligating or conventional bracket systems. Methods: A sample of 25 patients requiring orthodontic treatment was assessed based on the bracket type. Group 1 comprised 13 patients bonded with 0.022-in self-ligating brackets (SLB). Group 2 included 12 patients bonded with 0.022-in conventional brackets (CLB). Cone-beam computed tomography (CBCT) scans and a 3D program (Dolphin) assessed changes in transversal width of buccal bone (TWBB) and buccal bone thickness (BBT) before $\left(T_{1}\right)$ and 7 months after treatment onset $\left(T_{2}\right)$. Measurements on dental casts were performed using a digital caliper. Differences between and within groups were analyzed by Student's t-test; Pearson correlation coefficient was also calculated. Results: Significant mandibular expansion was observed for both groups; however, no significant differences were found between groups. There was significant decrease in mandibular buccal bone thickness and transversal width of buccal bone in both groups. There was no significant correlation between buccal bone thickness and dental arch expansion. Conclusions: There were no significant differences between self-ligating brackets and conventional brackets systems regarding mandibular arch expansion and changes in buccal bone thickness or transversal width of buccal bone.

Keywords: Orthodontic appliances. Corrective orthodontics. Orthodontic brackets.

Objetivo: o objetivo do presente estudo foi comparar as alterações dentoalveolares transversais e a espessura óssea da arcada inferior em pacientes submetidos ao tratamento ortodôntico utilizando sistemas de braquetes autoligáveis ou convencionais. Métodos: uma amostra de 25 pacientes requerendo tratamento ortodôntico foi recrutada com base no tipo de braquete. No Grupo 1, 13 pacientes foram tratados com braquetes autoligáveis (SLB, slot 0,022”); o Grupo 2 incluiu 12 pacientes, nos quais foram colados braquetes convencionais (CLB, slot 0,022 "). Utilizou-se tomografia computadorizada de feixe cônico e um programa 3D (Dolphin) para avaliar as alterações pré-tratamento $\left(\mathrm{T}_{1}\right)$ e 7 meses após o início desse $\left(\mathrm{T}_{2}\right)$. As medições em modelos de gesso foram realizadas com o auxílio de um paquímetro digital. As diferenças intergrupos, bem como intragrupo, foram analisadas por meio de teste $t$ de Student. Além disso, o coeficiente de correlação de Pearson foi utilizado. Resultados: alterações dentoalveolares significativas foram observadas em ambos os grupos. Entretanto, não houve diferenças significativas entre os grupos. Houve uma diminuição da espessura óssea na região posterior e das medidas transversais em ambos os grupos. Não houve uma correlação significativa entre a espessura óssea posterior e a expansão da arcada dentária, em nenhum dos dois sistemas de braquetes utilizados. Conclusões: comparando-se o uso dos aparelhos autoligáveis e convencionais, concluiu-se que não houve diferenças dentoalveolares significativas quanto à expansão da arcada inferior e quanto à espessura óssea posterior.

Palavras-chave: Ortodontia corretiva. Braquetes ortodônticos. Aparelhos ortodônticos.

\footnotetext{
${ }^{1}$ Full professor of Orthodontics, Universidade Norte do Paraná (UNOPAR), Londrina, Paraná, Brazil.

${ }^{2} \mathrm{MSc}$ in Orthodontics, Universidade Norte do Paraná (UNOPAR), Londrina, Paraná, Brazil.

${ }^{3}$ Professor of Orthodontics, Universidade do Sagrado Coração (USC), Bauru, São Paulo, Brazil.

${ }^{4} \mathrm{PhD}$ in Orthodontics, Universidade de São Paulo (USP), São Paulo, São Paulo, Brazil.
}

\footnotetext{
" The authors report no commercial, proprietary or financial interest in the products or companies described in this article.
}

\begin{abstract}
How to cite this article: Almeida MR, Futagami C, Conti ACCF, OltramariNavarro PVP, Navarro RL. Dentoalveolar mandibular changes with self-ligating versus conventional bracket systems: A CBCT and dental cast study. Dental Press J Orthod. 2015 May-June;20(3):50-7.

DOI: http://dx.doi.org/10.1590/2176-9451.20.3.050-057.oar
\end{abstract}

Submitted: June 02, 2014 - Revised and accepted: September 26, 2014

Contact address: Marcio Rodrigues de Almeida

Avenida Paris, 675 Jardim Piza, Londrina -PR - Brazil

CEP: 86041-120 - E-mail: marcioralmeida@uol.com.br 


\section{INTRODUCTION}

The ongoing search for innovation in Orthodontics has boosted the emergence or re-emergence of appliances so as to offer patients more comfort, shorter treatment time, improved post-treatment stability, and fewer side effects. Self-ligating brackets (SLB) came back into scene in the seventies, arising strong expectancy, and became popular in the nineties. Much empirical and anecdotal evidence as well as advantages were attributed to these appliances: increased patient comfort, better oral hygiene, increased patient cooperation, less chair time, shorter treatment time, greater patient acceptance, expansion, and less dental extractions. ${ }^{1-6}$

Correcting dental crowding without extractions or interproximal reductions requires an increase in arch perimeter in order to allow excellent teeth alignment. In the absence of distal movements, the dimensional changes of the arch involve transversal and buccal dental expansion. ${ }^{7}$ It is a well-known fact that both self-ligating and conventional ligating brackets (CLB) when used for non-extraction treatment of dental crowding produce dentoalveolar expansion. The amount of transversal increase depends on the mechanics applied in each case. ${ }^{7-11}$

Before the introduction of computerized tomography, it was not possible to visualize the buccal bone due to superposition that occurred in 2D radiographs. ${ }^{12,13}$ To achieve successful orthodontic treatment, the limits of orthodontic movement must be respected, in order to prevent iatrogenic effects to the sustaining and protection periodontium, such as gingival recessions, dehiscence and bone fenestrations. Studies prior to cone-beam computed tomography (CBCT) scans assessed only radiographs and dental casts, both of which used to be regarded as gold standards. Improvements in CBCT scans revealed it to be a reliable method, which offers an excellent visualization of the actual structures. ${ }^{14,15}$ Timock et al ${ }^{16}$ investigated the accuracy and reproducibility of measurements of alveolar bone height and thickness by means of CBCT imaging. They found good precision and accuracy for both measurements. ${ }^{16}$

The transversal response of the mandibular dental arch treated with CLB has been widely studied in the literature, especially the dentoalveolar response on dental casts. ${ }^{7,10,17,18}$ However, little is known regarding CBCT scans used to assess the mandibular alveolar bone of the posterior region, where buccal bone can be detected and quantified. ${ }^{19}$ This study aims at testing the null hypothesis that there is no difference, regarding changes in transversal width and buccal bone thickness in the mandibular arch, between patients undergoing the initial phase of orthodontic treatment (7 months) with SLB and CLB systems.

\section{MATERIAL AND METHODS}

This research protocol was approved by Universidade Norte do Paraná (UNOPAR, Londrina/PR, Brazil) Institutional Review Board. Patients and guardians were fully informed about the study and its implications, and signed a consent form.

For this prospective study, power analysis showed that a sample size of 12 patients in each group would give $80 \%$ probability to detect a real difference of $1.4 \mathrm{~mm}$ in intermolar distance and $0.2 \mathrm{~mm}$ in bone thickness, with a $95 \%(p<0.05)$ significance level. ${ }^{20}$ The sample for the present prospective randomized study was treated at Universidade Norte do Paraná (UNOPAR, Londrina, PR, Brazil) from 2009 to 2012. All patients had complete orthodontic records taken at the beginning $\left(\mathrm{T}_{1}\right)$ of treatment and 7 months after treatment onset $\left(\mathrm{T}_{2}\right)$, including study models and CBCT scans. In selecting the sample, the following inclusion criteria were applied: patients with Angle Class I malocclusion, moderate-to-severe lower dental crowding (3.0 to $7.0 \mathrm{~mm}$ ), absence of diastema, absence of posterior crossbite, complete permanent teeth (except for third molars). Patients were randomly divided into two groups: SLB and CLB. Out of the selected individuals, none were excluded after treatment onset. Premolars extraction and tooth wear were not included in the proposed treatment.

Group 1 (G1) comprised 13 patients treated with $0.022 \times 0.027$-in slot SLB (EasyClip Aditek, Cravinhos/SP, Brazil), with initial mean age of 18.58 years $(\mathrm{SD}=5.43)$. Group $2(\mathrm{G} 2)$ comprised 12 patients treated with $0.022 \times 0.028$-in slot CLB (3M Unitek, Monrovia, Calif., USA), with initial mean age of 21.61 years $(\mathrm{SD}=6.69)$. The archwires for Group 2 were tied to the brackets by means of a metallic ligature. Patients were orthodontically treated during initial leveling and alignment for six months, following the same sequence of round archwires: 0.013, 0.014 and 0.016-in nickel-titanium archwires, according to 
the manufacturers's (Aditek) prescription (Damon system). Each archwire remained in place for two months.

Cone-beam computed tomography scans were obtained from all patients at two time intervals prior to orthodontic treatment onset and 7 months after it. All CBCT scans were carried out by a single experienced radiologist using the same scanner (i-Cat Imaging Sciences International, Hatfield, Pennsylvania, USA) set up as follows: $22 \times 16 \mathrm{~cm}$ fov, $40 \mathrm{sec}$, $120 \mathrm{kVp}, 36 \mathrm{~mA}$. This scanner has high-resolution sensors and affords $0.4-\mathrm{mm}$ voxel images. ${ }^{21}$

CBCT scans were analyzed by one single operator who assessed mandibular bone changes by means of Dolphin 3D software (Version $11.5^{\circledR}$, Dolphin Imaging \& Management Solutions, Chatsworth, Calif., USA) with a level of sensitivity set at $25 \%$.

Coronal slices were selected for the bone measurements (Fig 1) and 1-mm thick cross-sections were made through the first molar (M1), second premolar (P2) and first premolar (P1), in the right and left mandibular arches. As for coronal slices, the mid portion of teeth (molars and premolars) was chosen. The point selected for buccal bone measurement was the most external prominence of the buccal bone $(\mathrm{EBB})$ in the root most apical portion (apex). At this same height, a point was projected from the parallel projection of the cusp point. The distance between the two points was determined as BBT, buccal bone thickness (Figs 2 and 3). Thus, changes in BBT were calculated by subtracting $\mathrm{T}_{1}$ from $\mathrm{T}_{2}$ values. For transversal width of the buccal bone, the EBB point was used on the right and left sides. The distance between right and left EBB was the transversal width of buccal bone (TWBB) (Fig 1). Similarly, TWBB changes were calculated by subtracting $T_{1}$ from $T_{2}$ values. In order to confirm whether transversal width and bone thickness measurements were taken on the same coronal slices, the mid region of each posterior teeth was used as reference to ensure consistency of slices.

Intermolar distances, intersecond premolar distances, and interfirst premolar distances were measured in dental casts (Fig 4) by means of a previously calibrated digital caliper (Mitutoyo Caliper, Japan). In order to measure the transversal distances, buccal cusp tips were selected for first and second mandibular premolars, while mesiobuccal cusp tips were selected for first molars.

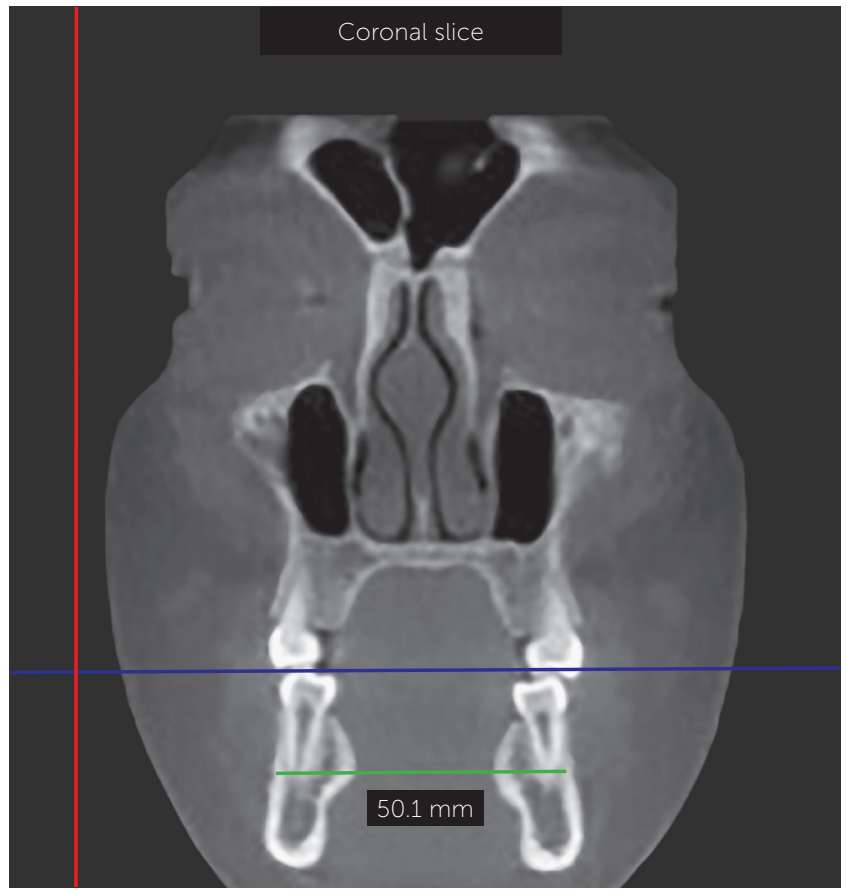

Figure 1 - Coronal slice and transversal width of buccal bone (TWBB).

\section{Statistical analysis}

To assess intra and interexaminer reliability, ten CBCT scans were randomly selected and remeasured four weeks apart by two operators. Intraexaminer error was assessed by means of paired t-test and Dahlberg's formula. Interexaminer reliability was assessed by intraclass correlation coefficient (ICC). Data were tested for normal distribution by means of Kolmogorov-Smirnov test. As data were normally distributed, parametric tests were applied. Results were described by parameters of mean and standard deviation of $T_{1}$ and $T_{2}$ measurements for both groups. Independent t-tests were used to compare the initial demographic data of both groups. Paired and unpaired t-tests were used to compare intra and intergroup changes. Finally, Pearson correlation coefficient was calculated to further explore the association between dental expansion and expansion of TWBB. In all statistical tests, the significance level was set at 5\%. ${ }^{22}$ All statistical analyses were performed with SPSS software for Windows version 17.0 (SPSS Inc, Chicago Ill.). 


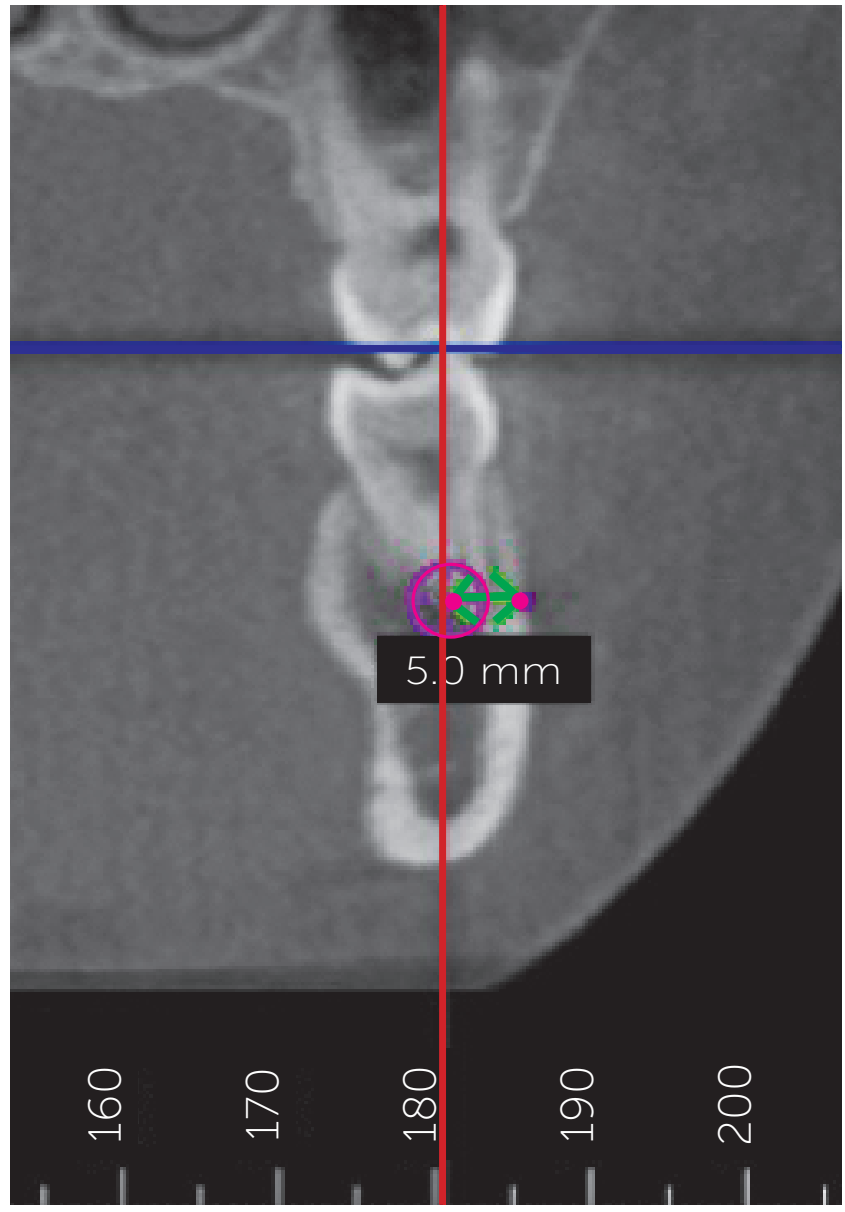

Figure 2 - Buccal bone thickness (BBT) measurements.

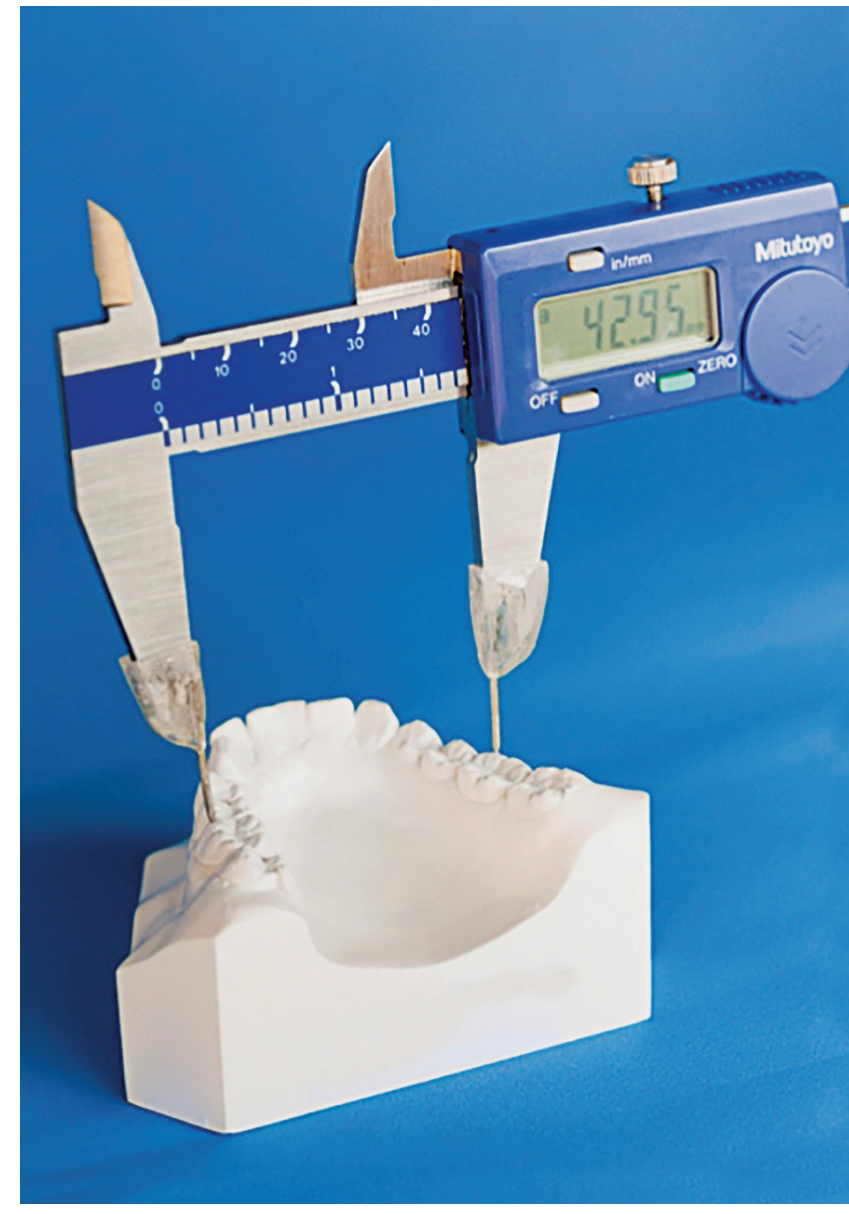

Figure 4 - Intermolar width measured on a dental cast by means of a digital caliper
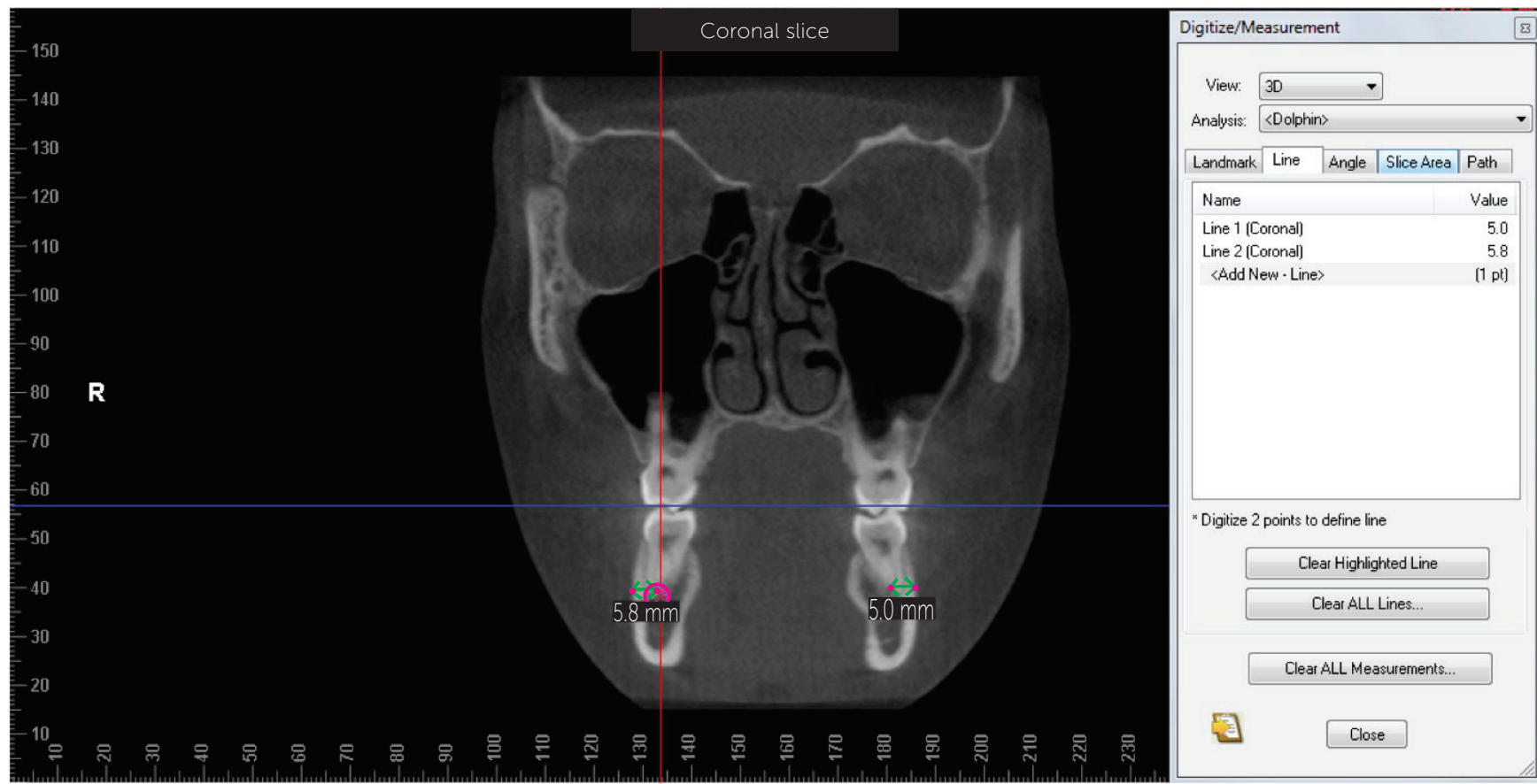

Figure 3 - Example of measurements for buccal bone thickness (BBT) of mandibular first molars. 


\section{RESULTS}

Systematic (paired t-test) and casual error (Dahlberg's formula) showed no intraexaminer difference. Intraclass correlation coefficients for bone thickness and transversal width of buccal bone measurements were 0.89 and 0.98 , respectively, thereby showing acceptable reliability. Random error ranged from 0.30 to $0.56 \mathrm{~mm}$ and from 0.53 to $1.08 \mathrm{~mm}$ for dental casts and CBCT measurements, respectively.

Patients' demographic distribution is presented in Table 1. Both samples were comparable at treatment onset regarding the following aspects: initial age, treatment time, intermolar distances, intersecond premolar distances, interfirst premolar distances, TWBB and BBT measurements. Means and standard deviation values for BBT and TWBB measurements at pretreatment $\left(\mathrm{T}_{1}\right), 7$ months after treatment onset $\left(T_{2}\right)$ and the changes observed $\left(T_{2}-T_{1}\right)$ are shown in Tables 2 to 4 .

Mandibular buccal bone thickness (BBT) decreased from $T_{1}$ to $T_{2}$ for both bracket types. BBT in the CLB group significantly decreased for P1L $(-1.51 \mathrm{~mm} ; \mathrm{p}=0.016), \operatorname{P1R}(-0.9 \mathrm{~mm} ; \mathrm{p}=0.039)$, P2R (-1.09 mm; $\mathrm{p}=0.007)$ and M1R (-0.79 mm; $\mathrm{p}=0.008)$. BBT in the SLB group significantly decreased for P1R (-0.88 mm, p = 0.019), P2L (-0.64 $\mathrm{mm} ; \mathrm{p}=0.002), \mathrm{P} 2 \mathrm{R}(-1.09 \mathrm{~mm}, \mathrm{p}<0.001)$ and M1R $(-0.54 \mathrm{~mm} ; \mathrm{p}=0.025)$. However, changes in TWBB measurements showed a slight decrease and were not considered statistically significant in either one of the groups: for the CLB group, the following measurements decreased: P1 (-0.21 mm; $\mathrm{p}=0.613)$, P2 (-0.66 mm; $\mathrm{p}=0.222)$ and M1 (-0.31 mm; $\mathrm{p}=0.611)$; as for the SLB group, the following measurements decreased: P1 $(-0.56 \mathrm{~mm} ; \mathrm{p}=0.076)$ and P2 $(-0.01 \mathrm{~mm} ; \mathrm{p}=0.980)$, with an increase in M1 $(0.10 \mathrm{~mm} ; \mathrm{p}=0.750)$.

Comparison between BBT and TWBB measurements from $T_{1}$ to $T_{2}$ revealed no significant differences between groups (Table 4). Additionally, no significant differences were found when comparing dental casts at treatment onset $\left(\mathrm{T}_{1}\right)$ and 7 months later $\left(\mathrm{T}_{2}\right)$ (Table 5$)$. An average increase of dental transversal distances occurred from $\mathrm{T}_{1}$ to $\mathrm{T}_{2}$, which was considered significant. Bracket type had no significant influence on changes in mandibular dental arch. Differences between SLB and CLB for interfirst
Table 1 - Patients' demographic distribution.

\begin{tabular}{|lccc}
\hline & SLB $(\mathbf{G} 1)(\mathbf{n}=13)$ & CLB $(\mathbf{G} 2)(\mathbf{n}=12)$ & $P$ \\
\hline Initial mean age (years) & $18.58 \pm 5.43$ & $21.61 \pm 6.69$ & 0.221 \\
\hline Treatment time (days) & $210.15 \pm 41.44$ & $218.17 \pm 46.60$ & 0.654 \\
\hline \multicolumn{4}{c}{ CBCT scans } \\
P1L BBT $(\mathrm{mm})$ & $2.34 \pm 2.59$ & $2.31 \pm 1.32$ & 0.972 \\
\hline P1R BBT $(\mathrm{mm})$ & $2.65 \pm 2.23$ & $2.44 \pm 1.21$ & 0.788 \\
\hline P2L BBT $(\mathrm{mm})$ & $4.64 \pm 2.38$ & $4.02 \pm 3.56$ & 0.613 \\
\hline P2R BBT $(\mathrm{mm})$ & $4.82 \pm 2.71$ & $4.92 \pm 2.11$ & 0.927 \\
\hline M1L BBT $(\mathrm{mm})$ & $6.24 \pm 2.29$ & $6.49 \pm 2.10$ & 0.783 \\
\hline M1R BBT $(\mathrm{mm})$ & $6.70 \pm 2.78$ & $6.87 \pm 1.48$ & 0.856 \\
\hline P1 TWBB $(\mathrm{mm})$ & $40.37 \pm 2.43$ & $38.94 \pm 2.58$ & 0.175 \\
\hline P2 TWBB $(\mathrm{mm})$ & $49.35 \pm 4.44$ & $49.17 \pm 4.07$ & 0.928 \\
\hline M1 TWBB $(\mathrm{mm})$ & $59.04 \pm 4.86$ & $59.16 \pm 4.45$ & 0.956 \\
\hline & Dental cast measurements $(\mathrm{mm})$ & \\
\hline 4-4 width $(\mathrm{mm})$ & $33.95 \pm 1.87$ & $33.37 \pm 2.36$ & 0.749 \\
\hline 5-5 width $(\mathrm{mm})$ & $38.42 \pm 2.18$ & $38.57 \pm 2.69$ & 0.888 \\
\hline 6-6 width $(\mathrm{mm})$ & $44.85 \pm 1.68$ & $44.37 \pm 2.76$ & 0.612 \\
\hline
\end{tabular}

M1 = first molar, $\mathrm{P} 2$ = second premolar and P1 = first premolar.

Table 2 - Mean and standard deviation at the beginning of treatment $\left(T_{1}\right)$ and 7 months after treatment onset $\left(T_{2}\right)$, regarding changes in buccal bone thickness and transversal width of buccal bone (CBCT measurements) for the CLB group.

\begin{tabular}{|ccccc}
\hline Measurements & $\mathrm{T}_{1}$ & $\mathrm{~T}_{2}$ & Diff. & P value \\
\hline P1L BBT $(\mathrm{mm})$ & $2.31 \pm 1.32$ & $0.80 \pm 1.86$ & -1.51 & $0.016^{*}$ \\
\hline P1R BBT $(\mathrm{mm})$ & $2.44 \pm 1.21$ & $1.54 \pm 1.46$ & -0.90 & $0.039^{*}$ \\
\hline P1 TWBB $(\mathrm{mm})$ & $38.94 \pm 2.58$ & $38.73 \pm 2.88$ & -0.21 & 0.613 \\
\hline P2L BBT $(\mathrm{mm})$ & $4.02 \pm 3.56$ & $3.14 \pm 2.31$ & -0.88 & 0.165 \\
\hline P2R BBT $(\mathrm{mm})$ & $4.92 \pm 2.11$ & $3.83 \pm 2.01$ & -1.09 & $0.007^{*}$ \\
\hline P2 TWBB $(\mathrm{mm})$ & $49.17 \pm 4.07$ & $48.52 \pm 3.72$ & -0.66 & 0.222 \\
M1L BBT $(\mathrm{mm})$ & $6.49 \pm 2.10$ & $6.18 \pm 1.55$ & -0.31 & 0.292 \\
\hline M1R BBT $(\mathrm{mm})$ & $6.87 \pm 1.48$ & $6.08 \pm 1.76$ & -0.79 & $0.008^{*}$ \\
\hline M1 TWBB $(\mathrm{mm})$ & $59.16 \pm 4.45$ & $58.90 \pm 4.34$ & -0.26 & 0.611 \\
\hline
\end{tabular}

* $\mathrm{P}<0.05 . \mathrm{M} 1$ = first molar, $\mathrm{P} 2$ = second premolar and $\mathrm{P} 1$ = first premolar.

Table 3 - Mean and standard deviation at the beginning of treatment $\left(T_{1}\right)$ and 7 months after treatment onset $\left(T_{2}\right)$, regarding changes in buccal bone thickness and transversal width of buccal bone (CBCT measurements) SLB group.

\begin{tabular}{|ccccc|}
\hline Measurements & $\mathrm{T}_{1}$ & $\mathrm{~T}_{2}$ & Diff. & P value \\
\hline P1L BBT $(\mathrm{mm})$ & $2.34 \pm 2.59$ & $1.69 \pm 1.64$ & -0.66 & 0.177 \\
\hline P1R BBT $(\mathrm{mm})$ & $2.65 \pm 2.23$ & $1.77 \pm 2.01$ & -0.88 & $0.019^{*}$ \\
\hline P1 TWBB $(\mathrm{mm})$ & $40.37 \pm 2.43$ & $39.82 \pm 2.67$ & -0.56 & 0.076 \\
\hline P2L BBT $(\mathrm{mm})$ & $4.64 \pm 2.38$ & $4.00 \pm 2.42$ & -0.64 & $0.002^{*}$ \\
\hline P2R BBT $(\mathrm{mm})$ & $4.82 \pm 2.71$ & $3.73 \pm 2.40$ & -1.09 & $<0.001^{* *}$ \\
\hline P2 TWBB $(\mathrm{mm})$ & $49.35 \pm 4.44$ & $49.34 \pm 4.13$ & -0.01 & 0.980 \\
\hline M1R BBT $(\mathrm{mm})$ & $6.24 \pm 2.29$ & $5.93 \pm 2.43$ & -0.32 & 0.158 \\
\hline M1R BBT $(\mathrm{mm})$ & $6.70 \pm 2.78$ & $6.16 \pm 2.63$ & -0.54 & $0.025^{*}$ \\
\hline M1 TWBB $(\mathrm{mm})$ & $59.04 \pm 4.86$ & $58.94 \pm 4.79$ & -0.10 & 0.750 \\
\hline
\end{tabular}

* $\mathrm{P}<0.05$. ${ }^{* *} \mathrm{P}<0.01$. M1 = first molar, $\mathrm{P} 2=$ second premolar and $\mathrm{P} 1=$ first premolar. 
Table 4 - Means and standard deviation at the beginning of treatment $\left(T_{1}\right)$ and 7 months after treatment onset $\left(T_{2}\right)$ measured by CBCT and comparing CLB and SLB groups.

\begin{tabular}{|ccccc}
\hline Measurements & SLB $(\mathrm{G} 1)(\mathbf{n}=\mathbf{1 3})$ & CLB $(\mathbf{G} 2)(\mathbf{n}=\mathbf{1 2})$ & Diff. & P value \\
\hline P1L BBT $(\mathrm{mm})$ & $-0.66 \pm 1.65$ & $-1.51 \pm 1.84$ & 0.85 & 0.234 \\
\hline P1R BBT $(\mathrm{mm})$ & $-0.88 \pm 1.17$ & $-0.90 \pm 1.34$ & 0.02 & 0.964 \\
\hline P1 TWBB $(\mathrm{mm})$ & $-0.56 \pm 1.04$ & $-0.21 \pm 1.38$ & -0.35 & 0.475 \\
P2L BBT $(\mathrm{mm})$ & $-0.64 \pm 0.57$ & $-0.88 \pm 2.06$ & 0.25 & 0.681 \\
\hline P2R BBT $(\mathrm{mm})$ & $-1.09 \pm 0.83$ & $-1.09 \pm 1.16$ & 0.00 & 0.995 \\
P2 TWBB $(\mathrm{mm})$ & $-0.01 \pm 1.10$ & $-0.66 \pm 1.76$ & 0.65 & 0.275 \\
\hline M1L BBT $(\mathrm{mm})$ & $-0.32 \pm 0.75$ & $-0.31 \pm 0.97$ & 0.01 & 0.992 \\
\hline M1R BBT $(\mathrm{mm})$ & $-0.54 \pm 0.77$ & $-0.79 \pm 0.85$ & 0.25 & 0.452 \\
\hline M1 TWBB $(\mathrm{mm})$ & $-0.10 \pm 1.15$ & $-0.26 \pm 1.72$ & 0.16 & 0.537 \\
\hline
\end{tabular}

M1 = first molar, P2 = second premolar and P1 = first premolar

Table 5 - Means and standard deviation at the beginning of treatment $\left(T_{1}\right)$ and 7 months after treatment onset $\left(T_{2}\right)$ measured in dental casts and comparing CLB and SLB groups.

\begin{tabular}{ccccc}
\hline Measurements & SLB $(\mathbf{G} 1)(\mathbf{n}=\mathbf{1 3})$ & $\left.\mathrm{CLB}_{\mathbf{B}} \mathbf{( \mathbf { 2 }}\right)(\mathbf{n}=\mathbf{1 2})$ & Diff. & p value \\
\hline 4-4 width & $1.27 \pm 1.95$ & $1.87 \pm 2.30$ & -0.60 & 0.489 \\
5-5 width & $2.10 \pm 1.00$ & $1.75 \pm 1.33$ & 0.35 & 0.465 \\
\hline 6-6 width & $0.92 \pm 0.88$ & $0.46 \pm 0.77$ & 0.46 & 0.180 \\
\hline
\end{tabular}

Table 6 - Pearson correlation coefficient between transversal width of buccal bone (TWBB) and dental expansion within the two bracket system groups.

\begin{tabular}{ccc}
\hline Measurements & $\mathbf{r}$ & $\mathbf{P}$ \\
\hline P1 TWBB & 0.15 & 0.467 \\
P2 TWBB & 0.28 & 0.176 \\
\hline M1 TWBB & 0.09 & 0.676 \\
\hline
\end{tabular}

M1 = first molar, P2 = second premolar and P1 = first premolar

premolar width, intersecond premolar width and intermolar width were $-0.6 \mathrm{~mm}(\mathrm{p}=0.489), 0.35 \mathrm{~mm}$ $(\mathrm{p}=0.465)$ and $0.46 \mathrm{~mm}(\mathrm{p}=0.180)$, respectively.

Furthermore, no statistically significant association was found between transversal width of buccal bone (TWBB) and dental expansion (Table 6).

\section{DISCUSSION}

In this sample, patients were treated by different dentists, but in order to obtain more reliable results, measurements were made by only one previously calibrated examiner. The error of the method used to assess intra and interexaminer reliability proved to be small. No significant differences were found between measurements made by two operators at two different time points. Interexaminer analysis showed that errors ranged from 0.30 to $1.08 \mathrm{~mm}$. This may have occurred due to high resolution images offering excellent view without overlapping structures.

A disadvantage of the CBCT method is its greater radiation dose in comparison to conventional radiographs (periapical and panoramic). However, CBCT is an invaluable tool in orthodontic research. Good to excellent reliability of CBCT scans used for detection of bone defects was demonstrated by Misch et al. ${ }^{23}$ Furthermore, when compared to bidimensional radiographs, CBCT showed great reliability and offered advantages when detecting and quantifying bone fissures and fenestrations, as well as periodontal defects in the buccal bone. ${ }^{24}$

Mandibular arch bone expansion studies with CBCT scans comparing SLB and CLB are rare in the literature. And few studies have assessed the maxillary arch response to SLB and CLB systems. ${ }^{19}$ Nonetheless, some studies compared arch expansion on dental casts and on digitized models, which may offer great accuracy. ${ }^{7,10,11}$ Claims have been made that SLB can result in broader arch forms in comparison to CLB. ${ }^{4}$ Thus, this study aimed at testing the null hypothesis that there are no significant differences in the amount of expansion of the mandibular arch (dental and alveolar bone changes) during the first 7 months of alignment and leveling when either SLB or CLB systems are used, as demonstrated by analysis on CBCT and dental casts.

According to Birnie, ${ }^{25}$ Damon divulged his theory that by using SLB with low friction and light forces more stable biological results could be produced. Damon, ${ }^{4}$ based on empirical and anedotical evidence, attributed advantages to self-ligating brackets, among which is the passive expansion of the arches. The Damon SLB system claims that post-treatment computed tomography images show transverse arch development and normal alveolar bone on buccal surface. Low friction and low force are purported to be good to physiologically rebuild the alveolar bone. ${ }^{26}$

The three-dimensional capability of CBCT makes it possible to noninvasively assess alveolar bone changes for mandibular posterior teeth. We found that BBT and TWBB measurements decreased from $T_{1}$ to $T_{2}$ for both groups. A significant difference occurred for the 
majority of measurements regarding $B B T$ from $T_{1}$ to $T_{2}$ for both groups. There was significant difference for the following measurements, from $\mathrm{T}_{1}$ to $\mathrm{T}_{2}$, regarding $\mathrm{BBT}$ changes: CLB group - P1L (-1.51 mm, $\mathrm{p}=0.016), \mathrm{P} 1 \mathrm{R}$ $(-0.90 \mathrm{~mm}, \mathrm{p}=0.039), \mathrm{P} 2 \mathrm{R}(-1.09 \mathrm{~mm}, \mathrm{p}=0.007)$, M1R (-0.79 mm, $\mathrm{p}=0.008)$; SLB group $-\mathrm{P} 1 \mathrm{R}$ $(-0.88 \mathrm{~mm}, \mathrm{p}=0.019), \mathrm{P} 2 \mathrm{~L}(-0.64 \mathrm{~mm}, \mathrm{p}=0.002)$, P2R (-1.09 mm, p < 0.001), M1R (-0.54 mm, $\mathrm{p}=0.025)$. However, no significant differences were found between groups. Furthermore, no significant differences from $T_{1}$ to $T_{2}$ were observed between and within groups for TWBB.

The results of the present study confirm findings in the literature showing similar behaviors for both brackets, particularly with regard to dental expansion assessed by means of dental casts. Mandibular arch alignment resulted in transverse expansion irrespective of the appliance system used. Interfirst premolar distances, measured on dental casts with a digital caliper in both groups, increased (SLB, $1.27 \mathrm{~mm}$; CLB, $1.87 \mathrm{~mm}$ ). This result is similar to those found by Fleming et al, ${ }^{7}$ with an increase of $0.85 \mathrm{~mm}$ and $1.17 \mathrm{~mm}$ for SLB and CLB, respectively. However, the change was not significantly different between the two bracket systems. Further corroborating these findings, Vajaria el $\mathrm{al}^{11}$ also found expansion in interfirst premolar distances. As for intersecond premolar distances, there was an increase of $2.10 \mathrm{~mm}$ for SLB and $1.75 \mathrm{~mm}$ for CLB; however, this increase was similar for both groups. Once again, the results yielded by the present study are similar to those obtained by Fleming et $\mathrm{al}^{7}(\mathrm{SLB}=1.43 \mathrm{~mm}$, and $\mathrm{CLB}=1.72 \mathrm{~mm})$. Nevertheless, contrary to our findings, Vajaria et $\mathrm{a}^{11}$ found a larger increase for the self-ligating group $(4.35 \mathrm{~mm}$ in comparison to $2.6 \mathrm{~mm}$ for the conventional group). Regarding intermolar distances, there was an increase ranging from 1.4 to $2.4 \mathrm{~mm}$ for SLB, and from 0.43 to $1.85 \mathrm{~mm}$ for CLB. $7,9,10,11,17,27,28$ On the other hand, a decrease in intermolar distance was observed in only one study in which cases were treated by means of premolar extractions. ${ }^{28}$ We found nonsignificant increases of mandibular first intermolar width for both SLB and CLB groups, and there was no significant difference between the two bracket groups. The present study showed molar expansion of $0.92 \mathrm{~mm}$ and $0.46 \mathrm{~mm}$ for SLB and CLB, respectively. This result is in accordance with the study by Vajaria et al. ${ }^{11}$ Nonetheless, Pandis et $\mathrm{al}^{10,17}$ and Fleming et $\mathrm{al}^{7}$ found that SLB expanded more than CLB in the molars region, and this difference was considered statistically significant.

When the Pearson correlation coefficient was assessed, we found that the alveolar buccal bone did not follow dental expansion. Therefore, the statements wherein self-ligating brackets produce physiological and passive movements of the arches were not confirmed in this study, at least 7 months after orthodontic treatment onset. Regarding buccal bone changes, it seems that self-ligating appliances do not offer any advantages over the conventional bracket system. Thus, the null hypothesis of the present study was accepted; in other words, no significant differences were found between self-ligating and conventional brackets systems regarding mandibular buccal bone plate expansion or dentoalveolar expansion.

\section{CONCLUSIONS}

" There is no difference between patients treated with self-ligating brackets or conventional brackets, regarding mandibular dentoalveolar expansion.

» There is no difference between patients treated with self-ligating brackets or conventional brackets, regarding buccal bone plate changes (mandibular buccal bone thickness and transversal width of buccal bone).

» There were no significant correlations between buccal bone plate changes and dentoalveolar expansion within groups. 


\section{REFERENCES}

1. Stolzenberg J. The efficiency of the Russell attachment. Am J Orthod Oral Surg 1946:32:572-82

2. Berger J. Self-ligation in the year 2000. J Clin Orthod. 2000;34:74-81.

3. Harradine N. The history and development of self-ligating brackets. Semin Orthod. 2008;14(1):5-18.

4. Damon $\mathrm{DH}$. The Damon low-friction bracket: a biologically compatible straightwire system. J Clin Orthod. 1998;32(11):670-80

5. Fleming PS, DiBiase AT, Lee RT. Self-ligating appliances: evolution or revolution? J Clin Orthod. 2008:42:641-51.

6. Rinchuse DJ, Miles PG. Self-ligating brackets: present and future. Am J Orthod Dentofacial Orthop. 2007:132(2):216-22.

7. Fleming PS, DiBiase AT, Sarri G, Lee RT. Comparison of mandibular arch changes during alignment and leveling with 2 preadjusted edgewise appliances. Am J Orthod Dentofacial Orthop. 2009;136(3):340-7.

8. Fleming PS, Johal A. Self-ligating brackets in orthodontics. A systematic review. Angle Orthod. 2010;80(3):575-84.

9. Chen SS, Greenlee GM, Kim JE, Smith CL, Huang GJ. Systematic review of selfligating brackets. Am J Orthod Dentofacial Orthop. 2010;137(6):726.e1-726.e18; discussion -7 .

10. Pandis N, Polychronopoulou A, Eliades T. Self-ligating vs conventional brackets in the treatment of mandibular crowding: a prospective clinical trial of treatment duration and dental effects. Am J Orthod Dentofacial Orthop. 2007:132(2):208-15

11. Vajaria R, Begole E, Kusnoto B, Galang MT, Obrez A. Evaluation of incisor position and dental transverse dimensional changes using the Damon system. Angle Orthod. 2011;81(4):647-52.

12. Tai K, Park JH, Mishima K, Shin JW. 3-dimensional cone-beam computed tomography analysis of transverse changes with Schwarz appliances on both jaws. Angle Orthod. 2011:81(4):670-7.

13. Yagci A, Veli I, Uysal T, Ucar Fl, Ozer T, Enhos S. Dehiscence and fenestration in skeletal Class I, II, and III malocclusions assessed with cone-beam computed tomography. Angle Orthod. 2012;82(1):67-74

14. Mah JK, Huang JC, Choo H. Practical applications of cone-beam computed tomography in orthodontics. J Am Dent Assoc. 2010;141 Suppl 3:7S-13S.

15. Sun Z, Smith T, Kortam S, Kim DG, Tee BC, Fields H. Effect of bone thickness on alveolar bone-height measurements from cone-beam computed tomography images. Am J Orthod Dentofacial Orthop. 2011;139(2):e117-27.
16. Timock AM, Cook V, McDonald T, Leo MC, Crowe J, Benninger BL, et at. Accuracy and reliability of buccal bone height and thickness measurements from cone-beam computed tomography imaging. Am J Orthod Dentofacial Orthop. 2011:140(5):734-44

17. Pandis N, Polychronopoulou A, Makou M, Eliades T. Mandibular dental arch changes associated with treatment of crowding using self-ligating and conventional brackets. Eur J Orthod. 2010;32(3):248-53.

18. Tecco S, Tete S, Perillo L, Chimenti C, Festa F. Maxillary arch width changes during orthodontic treatment with fixed self-ligating and traditional straight-wire appliances. World J Orthod. 2009;10(4):290-4.

19. Cattaneo P, Treccani M, Carlsson K, Thorgeirsson T, Myrda A, Cevidanes L, et al Transversal maxillary dento-alveolar changes in patients treated with active and passive self-ligating brackets: a randomized clinical trial using CBCT-scans and digital models. Orthod Craniofac Res. 2011:14(4):222-33.

20. Pandis N, Polychronopoulou A, Eliades T. Sample size estimation: an overview with applications to orthodontic clinical trial designs. Am J Orthod Dentofacial Orthop. 2011;140(4):e141-6.

21. Leite V, Conti AC, Navarro R, Almeida MR, Oltramari-Navarro P, Almeida R Comparison of root resorption between self-ligating and conventional preadjusted brackets using cone beam computed tomography. Angle Orthod. 2012:82(6):1078-82

22. Houston WJ. The analysis of errors in orthodontic measurements. Am J Orthod. 1983:83(5):382-90

23. Misch KA, Yi ES, Sarment DP. Accuracy of cone beam computed tomography for periodontal defect measurements. J Periodontol. 2006;77(7):1261-6.

24. Mol A, Balasundaram A. In vitro cone beam computed tomography imaging of periodontal bone. Dentomaxillofac Radiol. 2008;37(6):319-24.

25. Birnie D. The Damon passive self-ligating appliance system. Semin Orthod 2008:16:19-35

26. Yu YL, Qian YF. The clinical implication of self-ligating brackets. Shanghai Kou Qiang Yi Xue. 2007:16:431-5

27. Fleming PS, DiBiase AT, Lee RT. Randomized clinical trial of orthodontic treatment efficiency with self-ligating and conventional fixed orthodontic appliances. Am J Orthod Dentofacial Orthop. 2010;137(6):738-42.

28. Scott P, DiBiase AT, Sherriff M, Cobourne MT. Alignment efficiency of Damon3 self-ligating and conventional orthodontic bracket systems: a randomized clinical trial. Am J Orthod Dentofacial Orthop. 2008;134(4):470.e1-8 